OPEN ACCES $@($

\title{
Important marine areas for the conservation of northern rockhopper penguins within the Tristan da Cunha Exclusive Economic Zone
}

\author{
Antje Steinfurth ${ }^{1,2, *}$, Steffen Oppel ${ }^{1}$, Maria P. Dias ${ }^{3,4}$, Thomas Starnes ${ }^{1}$, \\ Elizabeth J. Pearmain ${ }^{3}$, Ben J. Dilley ${ }^{2}$, Delia Davies ${ }^{2}$, Mara Nydegger $^{1}$, Chris Bell $^{1}$, \\ Fabrice Le Bouard ${ }^{1}$, Alexander L. Bond ${ }^{1,5}$, Richard J. Cuthbert ${ }^{1,6}{ }^{\text {, }}$ Trevor Glass ${ }^{7}$, \\ Azwianewi B. Makhado ${ }^{2,8}$, Robert J. M. Crawford ${ }^{8}$, Peter G. Ryan' ${ }^{2}$, \\ Ross M. Wanless ${ }^{2,9}$, Norman Ratcliffe ${ }^{10}$ \\ ${ }^{1}$ RSPB Centre for Conservation Science, David Attenborough Building, Pembroke Street, Cambridge, CB2 3QZ, UK \\ ${ }^{2}$ FitzPatrick Institute of African Ornithology, University of Cape Town, Rondebosch 7700, South Africa \\ ${ }^{3}$ BirdLife International, David Attenborough Building, Pembroke Street, Cambridge, CB2 3QZ, UK \\ ${ }^{4}$ MARE - Marine and Environmental Sciences Center, ISPA - Instituto Universitário, 1100-304 Lisboa, Portugal \\ ${ }^{5}$ Bird Group, Department of Life Sciences, The Natural History Museum, Tring, HP23 6AP, UK \\ ${ }^{6}$ World Land Trust, Blyth House, Bridge Street, Halesworth, IP19 8AB, UK \\ ${ }^{7}$ Tristan Conservation Department, Edinburgh of the Seven Seas, Tristan da Cunha, TDCU 1ZZ, South Atlantic \\ ${ }^{8}$ Department of Environment, Forestry and Fisheries, PO Box 52126, Cape Town 8000, South Africa \\ ${ }^{9}$ Institute of Marine Affairs and Resource Management, National Taiwan Ocean University, Keelung, 20224, Taiwan \\ ${ }^{10}$ British Antarctic Survey, High Cross, Madingley Road, Cambridge, CB3 0ET, UK
}

\begin{abstract}
The designation of Marine Protected Areas has become an important approach to conserving marine ecosystems that relies on robust information on the spatial distribution of biodiversity. We used GPS tracking data to identify marine Important Bird and Biodiversity Areas (IBAs) for the Endangered northern rockhopper penguin Eudyptes moseleyi within the Exclusive Economic Zone (EEZ) of Tristan da Cunha in the South Atlantic. Penguins were tracked throughout their breeding season from 3 of the 4 main islands in the Tristan da Cunha group. Foraging trips remained largely within the EEZ, with the exception of those from Gough Island during the incubation stage. We found substantial variability in trip duration and foraging range among breeding stages and islands, consistent use of areas among years and spatial segregation of the areas used by neighbouring islands. For colonies with no or insufficient tracking data, we defined marine IBAs based on the mean maximum foraging range and merged the areas identified to propose IBAs around the Tristan da Cunha archipelago and Gough Island. The 2 proposed marine IBAs encompass $2 \%$ of Tristan da Cunha's EEZ, and are used by all northern rockhopper penguins breeding in the Tristan da Cunha group, representing $~ 90 \%$ of the global population. Currently, one of the main threats to northern rockhopper penguins within the Tristan da Cunha EEZ is marine pollution from shipping, and the risk of this would be reduced by declaring waters within 50 nautical miles of the coast as 'areas to be avoided'.
\end{abstract}

KEY WORDS: Eudyptes - Important Bird and Biodiversity Area - Marine protected area . Penguin $\cdot$ Seabird $\cdot$ Tracking

\section{INTRODUCTION}

Anthropogenic impacts on the marine environment are widespread and increasing, resulting in detri-

${ }^{*}$ Corresponding author: antje.steinfurth@rspb.org.uk mental impacts upon marine biodiversity (Halpern et al. 2008, 2015). The designation of Marine Protected Areas (MPAs) is among the suite of conservation measures available to mitigate such impacts (Agardy 
1994, Wood et al. 2008). In 2010, the Convention for Biological Diversity (CBD) committed to conserve 'areas of particular importance for biodiversity' with the ultimate aim to protect at least $10 \%$ of coastal and marine areas by 2020 (referred to as Aichi Biodiversity Target 11, CBD 2010), which has provided impetus for the designation of MPAs globally. Until recently, MPAs have been relatively small and were located primarily in inshore habitats (Game et al. 2009, Fox et al. 2012), but in the past decade, the designation of increasingly large pelagic MPAs within the Exclusive Economic Zone (EEZ) around oceanic islands has made a significant contribution to progress towards the Aichi Target 11 (Game et al. 2009, De Santo 2013, Hill et al. 2015). By December 2019, $7.6 \%$ of all seas, $17.7 \%$ of EEZs and $1.2 \%$ of Areas Beyond National Jurisdiction (ABNJ) were designated as MPAs (UNEP-WCMC et al. 2019). This progress is encouraging, although concerns have been expressed that the drive to meet percentage targets might compromise MPA quality and favour the designation of areas where no competing interests occur (De Santo 2013, Hill et al. 2015, Sala et al. 2018).

Seabirds are among the most threatened of marine taxa because of pressures from invasive predators, climate change, fisheries and pollution (Dias et al. 2019). They usually breed colonially on land, such that the at-sea distributions of many species are clustered in spatially predictable aggregations within EEZs during the breeding season (Harrison et al. 2018, Oppel et al. 2018). The site-based conservation of seabirds in the marine environment has been spearheaded by the recognition of marine Important Bird and Biodiversity Areas (IBAs) from tracking data (Ronconi et al. 2012, Lascelles et al. 2016). Marine areas are defined as globally important IBAs if a globally threatened species regularly occurs in an area (IBA criterion A1; Lascelles et al. 2016) or if they hold congregations of $\geq 1 \%$ of the global population of a species on a regular or predictable basis (IBA criterion A4). While marine IBAs carry no legislative power, delimiting distribution hotspots is viewed as a fundamental precursor to evidence-based MPA designs or systematic marine spatial planning (Lascelles et al. 2016, Smith et al. 2019). Across several Southern Ocean islands, for example, the use of multi-species tracking data has been essential to inform marine spatial planning for seabirds within the EEZs of the respective archipelagos (Patterson et al. 2016, Dias et al. 2017, Baylis et al. 2019, Heerah et al. 2019).

The northern rockhopper penguin Eudyptes moseleyi breeds only in the Tristan da Cunha group of islands in the South Atlantic (which hosts $~ 90 \%$ of the world population) and on Amsterdam and St. Paul islands in the southern Indian Ocean (RZSS et al. 2018). The restricted distribution of this species, combined with population declines of $90-99 \%$ since the $19^{\text {th }}$ century, has led to its IUCN classification of Endangered (Cuthbert et al. 2009, BirdLife International 2018). The causes of the population decline are not fully understood, but changes in the marine environment (including increasing sea temperatures and reduction or displacement of prey), diseases and oil pollution are among the suspected causes (BirdLife International 2018). Whereas terrestrial threats to colonies at the South Atlantic breeding sites have been addressed (Cuthbert 2013), until recently, conservation actions in the marine environment have been hampered by a complete lack of data describing the spatial distribution of this species at sea. This information is, however, crucial to allow assessment of overlap with potential threats and to help authorities to implement appropriate conservation strategies where they will have the greatest benefit (RopertCoudert et al. 2019, Boersma et al. 2020).

In 2015, the UK government committed to its Blue Belt Programme to contribute to its obligations to meet Aichi Target 11. The Blue Belt aims to designate MPAs encompassing 4 million $\mathrm{km}^{2}$ of sea within the EEZs of the 14 UK Overseas Territories, including Tristan da Cunha (O'Leary et al. 2019). To support this initiative, we provide the first comprehensive description of the at-sea distribution of northern rockhopper penguins in the Tristan da Cunha group of islands to identify critical foraging areas used by this species within the Tristan da Cunha EEZ throughout the breeding season. We propose 2 marine IBAs for northern rockhopper penguins and recommend management measures to mitigate current and potential threats to this Endangered species.

\section{MATERIALS AND METHODS}

\subsection{Study area}

The Tristan da Cunha group consists of 4 main islands: Tristan da Cunha (home to $\sim 270$ people in the settlement Edinburgh of the Seven Seas), Inaccessible and Nightingale islands which form the Tristan da Cunha archipelago, and Gough Island located $380 \mathrm{~km}$ to the south-southeast (Fig. 1). Hereinafter, Tristan da Cunha is abbreviated to Tristan and all of the islands are referred to by their first name only. Gough lies to the south of the Subtropical Front (STF), while all the other islands are situated to the 


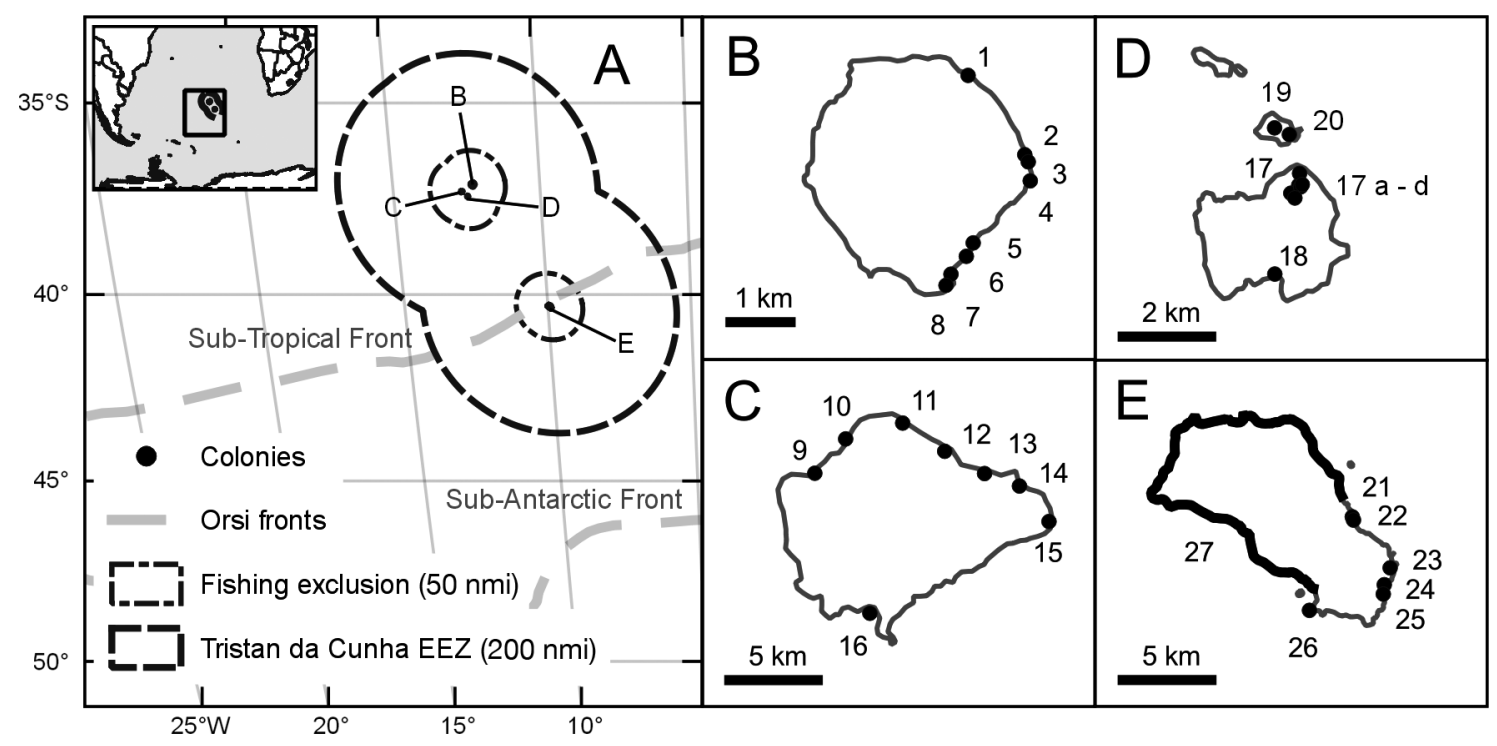

Fig. 1. Location of breeding colonies of northern rockhopper penguins in (A) the Tristan da Cunha archipelago and Gough Island in the South Atlantic Ocean, including: (B) Tristan da Cunha, (C) Inaccessible Island, (D) Nightingale Island (with adjacent Alex/Middle islet) and (E) Gough Island. Numbers refer to Colony IDs in Table S1. For (E), note that numerous colonies occur around the north, east and west coast of Gough, but their exact locations are poorly defined; the stretch of coast with counts based on beach surveys is therefore highlighted in black. EEZ: Exclusive Economic Zone; ocean fronts after Orsi et al. (1995)

north of it (Fig. 1). Gough and Inaccessible are World Heritage Sites, and Marine Nature Reserves have been designated within 12 nautical miles (nmi) of their shorelines. The Tristan EEZ extends $200 \mathrm{nmi}$ around the island group and encompasses approximately $750000 \mathrm{~km}^{2}$ (Fig. 1). Only fishing for rock lobster Jasus tristani is permitted within $50 \mathrm{nmi}(93 \mathrm{~km})$ around the coastlines of all islands (Fig. 1). This fishery, which uses pots to catch lobster in waters up to $150 \mathrm{~m}$ deep, provides the main income for the islanders. Limited commercial fishing for finfish is permitted under license $>50 \mathrm{nmi}$ from the islands, and mainly occurs over sea mounts in the southeast of the EEZ. Transiting ships are required to maintain a minimum safe clearing distance of $10 \mathrm{nmi}(18.5 \mathrm{~km})$ from land (Tristan da Cunha Ordinances 1983).

\subsection{Spatial and temporal extent of sampling}

We tracked northern rockhopper penguins at colonies on Nightingale (Fig. 1D, Sergeant Major, Colony ID 17; 18190 breeding pairs), Gough (Fig. 1E, Seal Beach, Colony ID 24; 1380 breeding pairs) and Inaccessible (Fig. 1C, Salt Beach, Colony ID 12; 31250 breeding pairs) (Fig. 1, see Table 1, Table S1 in the Supplement at www.int-res.com/articles/suppl/ n043p409_supp.pdf). These 3 colonies were selected because they hold a large proportion of the global population (23-27\%) and for logistical reasons of accessibility.

Like other Eudyptes penguins, northern rockhopper penguins have a synchronised breeding cycle divided into distinct breeding stages, each with different nest attendance patterns that impose constraints on their movements. Sampling of all these stages is therefore necessary to fully describe their at-sea distribution. Laying occurs in early September at the Tristan archipelago and $3 \mathrm{wk}$ later at Gough (Cuthbert 2013). Incubation takes about 32-34 d and is divided into 2 shifts between males and females (Williams 1995). Upon hatching, a single chick is guarded by the male for a further 20-26 d (broodguard stage) while females provision the brood (Cuthbert 2013). After this time, when both parents forage simultaneously and leave their chick unguarded, chicks gather into crèches (crèche stage) until they fledge in December in the Tristan archipelago or January on Gough (Williams \& Stone 1981, Cuthbert 2013).

\subsection{Tracking data collection}

Incubation trips were recorded at Gough in 2012 and 2013, and at Nightingale in 2012, 2013 and 2016 but not from Inaccessible Island. Brood-guard trips were recorded in 2012 and 2013 on both Gough and 
Nightingale, and in 2016 on Nightingale and Inaccessible. Crèche trips were recorded in 2012, 2013, and 2016 on Nightingale, where sufficient manpower and easy access to the colony allowed recapture of birds during a stage when they spend very little time ashore (see Table 1, Table S2).

Adult northern rockhopper penguins were captured by hand or a hand-held net at their nest site (incubation and brood-guard) or in the colony when feeding chicks (crèche) and equipped with GPS data loggers. We used 4 different models of GPS loggers: CatTraQ (Mr Lee Technologies, $45.7 \times 30.5 \times 12.7 \mathrm{~mm}, 25 \mathrm{~g}$ ), IGotU (Mobile Action Technology, $50 \times 34 \times 10 \mathrm{~mm}$, $25 \mathrm{~g}$ ) and Fastloc 2 (Sirtrack, $69 \times 28 \times 21 \mathrm{~mm}, 39 \mathrm{~g}$ ) in 2012 and 2013 and Pathtrack nanoFix GEO (on Nightingale) and Pathtrack nanoFix GEO+RT (on Inaccessible) (PathTrack, $54 \times 19 \times 15 \mathrm{~mm}, 24 \mathrm{~g}$ ) in 2016. CatTraQ and IGotU devices were removed from their plastic housings and the batteries were upgraded to $370 \mathrm{~A} \cdot \mathrm{h}$. CatTraQs were then encapsulated in resin and IGotU devices shrink-wrapped to waterproof the connections before deployment. Details of deployments and outcomes are presented in Table S2. The devices were attached to feathers on the dorsal midline of the bird's lower back using overlapping layers of black waterproof tape (Tesa 4651) and tape edges were sealed with cyanoacrylate glue (Wilson et al. 1997). Prior to release, birds were stained with a temporary animal marker (Porcimark, Jørgen Kruuse), so they could be easily identified for recapture. To reduce stress to individual birds, only 1 bird per nest was equipped, and different birds were captured during each breeding stage (incubation, brood-guard and crèche). Handling time was restricted to $15 \mathrm{~min}$ to minimise disturbance in the colony. All equipped birds returned to their brood and resumed breeding.

The heaviest device ( $39 \mathrm{~g}$ ) was $<3 \%$ of the weight of the smallest penguin equipped $(1.52 \mathrm{~kg})$ and most devices were on average $<2 \%$ of the body mass of the birds. This mass is unlikely to have affected foraging trips, because southern rockhopper penguins E. chrysocome fitted with $75 \mathrm{~g}$ GPS tags in the Falkland Islands increased trip durations in only 1 year out of 3 studied (Ludynia et al. 2012). The crosssectional dimensions of the device can be more important than mass due to the increased drag for diving animals (Wilson et al. 1986, Ropert-Coudert et al. 2007a,b). Our largest GPS device (Sirtrack Fastloc 2) had a cross-sectional area of $5.88 \mathrm{~cm}^{2}$, which represents on average $4 \%$ of a southern rockhopper penguin cross-section (mean: $40.1 \mathrm{~cm}$, range: 36.0$47.0 \mathrm{~cm}$; Ludynia et al. 2012). Adjusted for the approximately $20 \%$ larger body size of a northern rockhop- per penguin (Borboroglu \& Boersma 2013), the crosssectional area is likely $\leq 3 \%$, and we therefore considered drag effects to be negligible.

Loggers were programmed to sample positions every $0.75-3$ min during the brood-guard and crèche stage tracking periods (Table S3). During incubation, however, when foraging trips were expected to last up to $3 \mathrm{wk}$, we experimented with different sampling regimes to ensure that batteries lasted for complete foraging trips. Penguins tracked during incubation were therefore sampled at temporal resolutions ranging from 1 position every 10 min to every $5 \mathrm{~min}$ for $2 \mathrm{~h}$ per day (between 00:00-01:00 $\mathrm{h}$ and 12:0013:00 h) (Table S3). All devices only recorded positions when the bird was at the water surface.

On Nightingale and Gough, equipped birds were recaptured when seen returning from the sea or at return to the nest. Due to logistical constraints, visits to Inaccessible were limited to 2 trips. Birds were therefore equipped with Pathtrack nanoFix GEO+RT devices that download their data to a base station via a wireless UHF radio link, which eliminated the need to recapture the bird.

\subsection{Tracking data analysis}

We filtered inaccurate GPS locations by removing unrealistic points (resulting in speeds $>8 \mathrm{~km} \mathrm{~h}^{-1}$, based on swim speeds of southern rockhopper penguins from Marion Island; Brown 1987). When devices recorded consecutive trips, we separated data into foraging trips using the function 'tripSplit' in the $\mathrm{R}$ package 'track2kba' (Beal et al. 2020), and interpolated all at-sea tracking data to regular 1 min sampling intervals using a continuous, time-correlated random walk model implemented in the $\mathrm{R}$ package 'Crawl' (Johnson et al. 2011).

For each complete foraging trip, we calculated the trip duration from departure to return to the colony (days), and the maximum distance the bird travelled from the colony (foraging range, $\mathrm{km}$ ). Due to the different sampling regimes used during incubation, we expected that calculated trip parameters could differ solely due to the sampling regime. We therefore down-sampled all tracks that were recorded at a regular 10-60 min interval to 2 positions per day to match the lowest temporal resolution of any of our devices, re-calculated both trip parameters, and tested whether there was a significant difference between the original (high resolution) and downsampled (low resolution) trip parameters (Figs. S1 \& $\mathrm{S} 2$ ). We found no significant differences in trip dura- 
tion (mean difference: $0.38 \% ; p=0.881$, Fig. S1) and maximum foraging range (mean difference: $0.06 \%$; $\mathrm{p}=0.997$, Fig. S2) between the 2 sampling regimes, and therefore used our original data despite the various sampling schemes because the key quantity relevant for our main purpose of identifying marine IBAs (foraging range) was not affected by the sampling regime.

Based on foraging patterns observed in congeners (e.g. Barlow \& Croxall 2002a for macaroni penguin E. chrysolophus; Hull et al. 1997 for royal penguin E. schlegeli; Ludynia et al. 2013 and Masello et al. 2010 for southern rockhopper penguin), we then tested whether the 2 foraging trip parameters differed between sexes, breeding stages, colony and years by fitting separate linear mixed models for each parameter and comparing these models with a likelihood ratio test (Lewis et al. 2011). We included the individual bird as a random effect, and island, breeding stage, sex and year as fixed factors. We present estimated trip characteristics (mean parameter $\beta$ ) from the minimum adequate model with standard errors, and the respective test statistic and pvalue for the comparison among models. As residuals of trip durations during crèche were bimodal, we used the function 'Mclust' in the 'mclust' package (Fraley et al. 2012), with the number of clusters specified as 2 to classify trips as long or short, and conducted further analysis within these groups.

We defined marine foraging areas for 6 coherent subsets of data (differing by breeding stage and island) by calculating the kernel utilisation distribution and estimating the $50 \%$ isopleth using the function 'kernelUD' in the $\mathrm{R}$ package 'adehabitatHR' (Calenge 2006). We projected tracking data to a Lambert Azimuthal Equal Area projection centred on the islands, and used the most appropriate smoothing factor (h) for penguins, a fixed radius of $7 \mathrm{~km}$ following Dias et al. (2018). We then quantified the spatial overlap between foraging areas from different islands at the same breeding stage, and for different breeding stages from the same island by calculating Bhattacharyya's Affinity (BA) index (Fieberg \& Kochanny 2005) using the function 'kerneloverlap' in 'adehabitatHR'. This metric calculates the overlap between 2 utilisation distributions on a scale from 0 (no overlap) to 1 (complete overlap). Where sufficient tracking data from multiple years were available to calculate annual utilisation distributions (within stage and island), we further assessed consistency of utilisation distributions among years by calculating the BA of annual core foraging areas.

\subsection{Identification of marine IBAs}

We identified marine IBAs for northern rockhopper penguins using the $\mathrm{R}$ package 'track2kba' following procedures developed by BirdLife International (Lascelles et al. 2016, Beal et al. 2020) with revisions specific for penguins outlined in Dias et al. (2018). We analysed data separately for each island and breeding stage (Lascelles et al. 2016, Beal et al. 2020). Because we found little variability in the location of important areas between years within stages and specific colonies (see Section 3), we combined data for assessment of marine IBAs from all years per stage and island. Briefly, we first calculated the kernel utilisation distribution and estimated the $50 \%$ isopleth for all individual tracks (corresponding to the core foraging area of each tracked bird) for each island and breeding stage, and overlaid individual core foraging areas to identify areas where $>10 \%$ of tracked birds overlapped (Lascelles et al. 2016). We included multiple trips by the same individual, which only occurred during brood-guard, because we found no evidence of individual specialisation using the function 'IndEffectTest' in package 'track2kba' (Beal et al. 2020). We then assessed whether our datasets were representative of the tracked population using the function 'repAssess' in package 'track2kba' (Beal et al. 2020). If this representativeness was $>70 \%$, a dataset was deemed adequate to describe the at-sea distribution of penguins tracked from that island at the respective breeding stage, otherwise samples were considered insufficient for recognising utilisation distributions for the whole population. For datasets qualifying as being representative, we delineated marine IBAs using the function 'findKBA' in package 'track2kba' (Beal et al. 2020).

Given that the northern rockhopper penguin is classified as Endangered (BirdLife International 2018), and that all 4 main islands (Tristan, Inaccessible, Nightingale, Gough) and the small islet Alex (or Middle) adjacent to Nightingale each hold $\geq 1 \%$ of the global breeding population of the species (Fig. 1, Table S1), these sites, including their surrounding waters, meet the IBA criterion A1 (regular occurrence of a Globally Threatened species) and A4 (holds $\geq 1 \%$ of the global population). For colonies where no tracking data existed or where existing tracking data were not representative, we therefore defined marine IBAs based on the estimated mean maximum foraging radius derived from our tracking data (Soanes et al. 2016). We then merged the IBAs identified based on tracking data and those identified by radius around breeding colonies to propose a 
single combined IBA for the Tristan archipelago and Gough, respectively. Since all penguins must use the area around the colony during foraging trips (for commuting or foraging), we used the most recent population counts of colonies available (Table S1) and summed the colonies for each island to estimate the number of penguins frequently using these marine IBAs.

\subsection{Permits and animal ethics}

All methods were carried out in accordance with the Environmental Research permit provided by the Government of Tristan da Cunha. Animal ethics approval was given by the Animal Ethics committee of the University of Cape Town (2012-2013), the British Antarctic Survey Animal Welfare and Ethical Review Body and the Royal Society for the Protection of Birds' Animal Ethics Advisory Committee (2016), complying with the laws and regulations of the UK government and the guidance of the UK Animals (Scientific Procedures) Act 2013/63.

\section{RESULTS}

We obtained 212 complete and 22 incomplete foraging trips from 139 northern rockhopper penguins across the 3 islands and 3 breeding stages (Tables 1 \& S2). Penguins displayed marked variability in their spatial distributions during different stages of the breeding season and between islands.

\subsection{Foraging trip parameters}

There were significant differences among islands and breeding stages for trip duration (likelihood ratio test; $\left.\chi^{2}=166.95, \mathrm{p}<0.001\right)$ and maximum distance from the colony $\left(\chi^{2}=155.06, \mathrm{p}<0.001\right.$; Table 1$)$, but no differences among years once accounting for variation between islands and breeding stages (all $\mathrm{p} \leq$ 0.12).

Duration of trips was shortest for brood-guard trips and longest for incubation trips $\left(\chi^{2}=28.42, p<0.001\right.$; Table 1). Incubation trip durations averaged $6 \mathrm{~d}$ longer for males than females $(\beta=158.79 \pm 42.7)$, and $5 \mathrm{~d}$ shorter for males from Nightingale than from Gough $\left(\beta=-128.78 \pm 47.2 ; \chi^{2}=11.91, p=0.002 ;\right.$ Table 1$)$. During the crèche stage, both sexes performed 2 distinct trip types, with short trips lasting generally just $1 \mathrm{~d}$ and long trips lasting up to $3 \mathrm{wk}\left(\chi^{2}=33.52\right.$, $\mathrm{p}<0.001$; Table 1), but the duration of trips did not differ between the sexes $\left(\chi^{2}=0.15, p=0.7\right)$.

The foraging range during incubation was greater than during brood-guard ( $\beta=259.66 \pm 26.4$; Table 1 ). Incubation trip ranges differed among sexes, with males foraging farther from the colony than females $\left(\beta=158.79 \pm 47.2 ; \chi^{2}=19.43, p<0.001\right.$; Table 1$)$. Penguins from Gough had a greater foraging range during incubation than penguins from Nightingale, but there were no differences among sites during broodguard (Table 1). The cluster analysis found support for 2 discrete clusters in trip ranges during crèche separated by a cut-off distance of $45 \mathrm{~km}$. The 2 distinct trip types during the crèche stage differed considerably in their range $\left(\beta=212.13 \pm 43.6 ; \chi^{2}=18.95\right.$, $\mathrm{p}<0.001$ ): short trips were similar to those during the

Table 1. Trip characteristics for complete foraging trips of northern rockhopper penguins tracked from islands in Tristan da Cunha during the 3 different stages of their breeding cycle in 2012, 2013 and 2016 (mean and 95\% confidence interval). Representativeness (Rep.) is a measure of how representative the tracked sample is of the population distribution (values $>70 \%$ are considered adequate to represent the distribution of the population and are highlighted in bold; see Section 2)

\begin{tabular}{|c|c|c|c|c|c|c|c|c|}
\hline Stage & Sex & Type & Island & $\begin{array}{l}\text { No. of indi- } \\
\text { viduals with } \\
\text { complete trips }\end{array}$ & $\begin{array}{c}\text { No. of } \\
\text { trips }\end{array}$ & $\begin{array}{l}\text { Rep. } \\
(\%)\end{array}$ & $\begin{array}{l}\text { Trip duration } \\
\text { (d) }\end{array}$ & $\begin{array}{c}\text { Max. } \\
\text { foraging } \\
\text { range }(\mathrm{km})\end{array}$ \\
\hline \multirow[t]{4}{*}{ Incubation } & Male & All trips & Gough & 6 & 7 & 59.6 & $27.1(22.6-31.0)$ & $584(508-671)$ \\
\hline & & & Nightingale & 12 & 12 & 61.1 & $21.3(16.1-30.9)$ & $402(276-577)$ \\
\hline & Female & All trips & Gough & 4 & 4 & 59.6 & $15.7(11.5-20.0)$ & $337(84-556)$ \\
\hline & & & Nightingale & 12 & 13 & 61.1 & $16.3(7.8-35.0)$ & $277(141-559)$ \\
\hline \multirow[t]{3}{*}{ Brood-guard } & Female & All trips & Gough & 23 & 32 & 96.6 & $1.0(0.3-1.9)$ & $25(7-66)$ \\
\hline & & & Inaccessible & 6 & 7 & 11.8 & $1.4(0.6-2.5)$ & $38(20-56)$ \\
\hline & & & Nightingale & 42 & 99 & 98.6 & $1.2(0.3-3.1)$ & $34(7-76)$ \\
\hline \multirow[t]{2}{*}{ Crèche } & Male and & Long trips & Nightingale & 14 & 14 & 68.9 & $13.8(2.0-26.2)$ & $224(49-693)$ \\
\hline & female & Short trips & Nightingale & 14 & 24 & & $0.7(0.2-1.5)$ & $16(5-33)$ \\
\hline
\end{tabular}



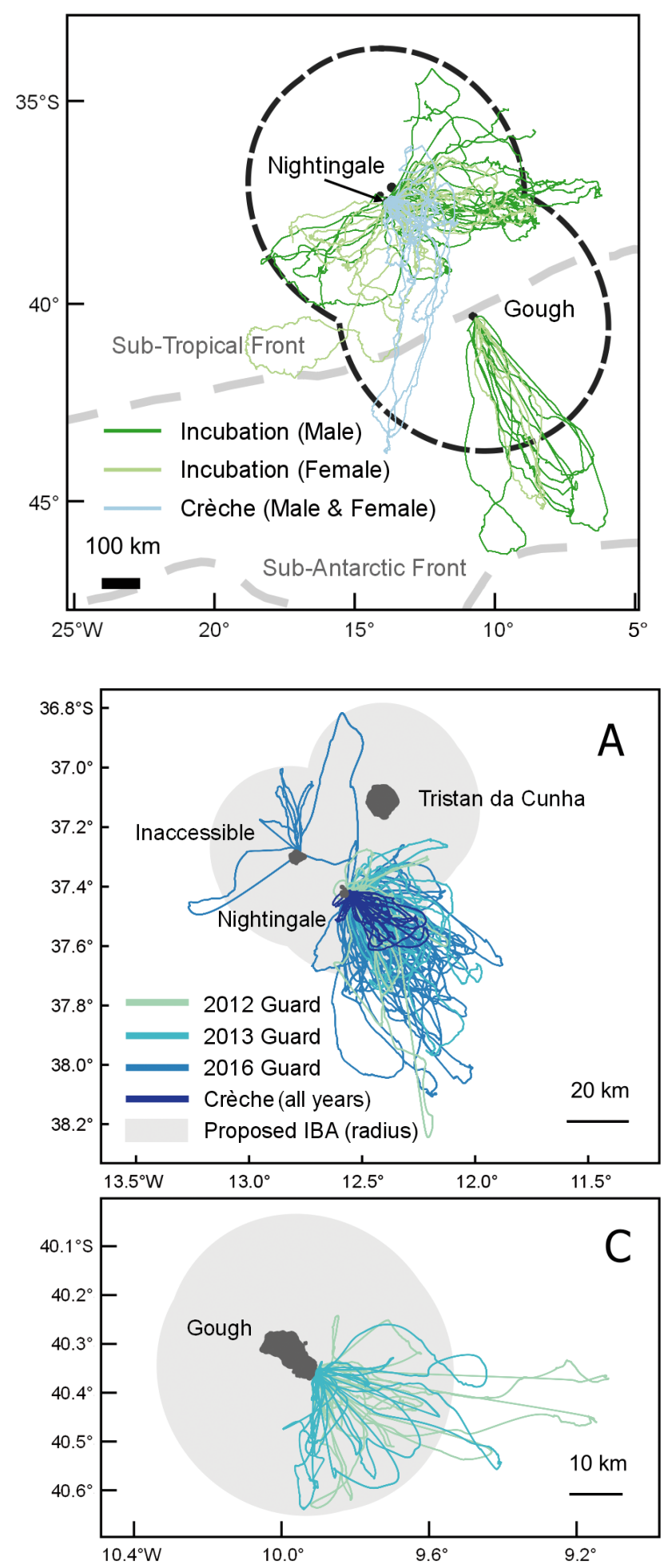

Fig. 2. Foraging trips (complete and incomplete) of northern rockhopper penguins tracked with GPS devices from Nightingale and Gough islands during the incubation stage, and while performing long trips when raising large chicks (crèche; Nightingale only). Black dashed line: Tristan da Cunha Exclusive Economic Zone (EEZ)

brood-guard stage, while the long trips were intermediate between brood-guard and incubation trips (Table 1). Penguins from all 3 islands remained within $80 \mathrm{~km}$ (43 $\mathrm{nmi}$ ) of their colony during broodguard and short crèche trips (Table 1).

\subsection{At-sea distribution}

During incubation, penguins from Nightingale dispersed mostly east-west and remained mainly within
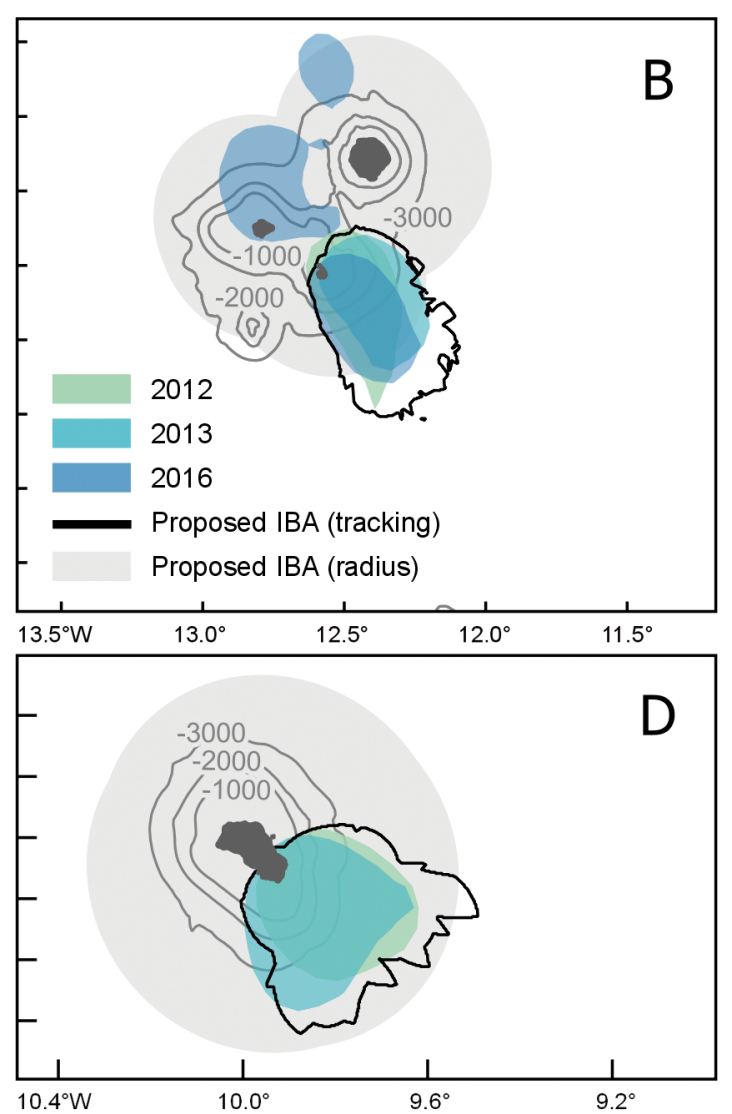

Fig. 3. (A) Chick-provisioning trips of northern rockhopper penguins tracked with GPS loggers during guard (only females) and crèche (males and females; short trips) and (B) the respective 50\% isopleths for 2012, 2013 and 2016, from Nightingale and Inaccessible islands. (C) Chick-provisioning trips and (D) the respective $50 \%$ isopleths from Gough Island for 2012 and 2013. Light grey area: the proposed marine Important Bird and Biodiversity Area (IBA) boundaries around untracked colonies and colonies with insufficient tracking data based on the average mean maximum foraging range obtained from tracked individuals $(32 \mathrm{~km})$. Thick black outline in $(B, D)$ : the proposed marine IBA boundaries derived directly from tracking data. 
the boundaries of the EEZ, while penguins from Gough oriented trips southwards towards the Subantarctic Front, often travelling outside the EEZ (Fig. 2). Penguins from Nightingale and Gough spent 90 and $57 \%$ of their foraging time during incubation within the EEZ, respectively.

Because of the different distances and direction travelled between breeding stages, the $50 \%$ kernel utilisation distributions between the incubation and brood-guard stages overlapped very little on Gough $(\mathrm{BA}=0.157)$. On Nightingale, foraging areas used by penguins during brood-guard trips also overlapped only marginally with incubation trips $(\mathrm{BA}=0.267$ ) but overlapped extensively with those during short crèche trips $(\mathrm{BA}=0.850$, Fig. $3 \mathrm{~A})$. The foraging areas of penguins from Gough and Nightingale during incubation and brood-guard did not overlap at all (Figs. $2 \& 3$ ) and those from Nightingale and Inaccessible overlapped only moderately during broodguard (BA =0.137, Fig. 3A,B).

In contrast to the low overlap between spatially distinct colonies, there was high overlap between utilisation distributions during brood-guard between years on Nightingale $(2012,2013$, and 2016, BA = 0.894-0.939, Fig. 3B) and on Gough (2012 and 2013, $\mathrm{BA}=0.946$, Fig. 3D), and we therefore pooled data among years to assess for marine IBAs.

\subsection{Identification of marine IBAs}

Because penguins travelled far and dispersed widely at sea during incubation (Table 1), none of our incubation tracking data were sufficiently representative of the tracked population to meet IBA data requirements (representativeness $<70 \%$, Table 1). During the brood-guard stage, however, females performed shorter trips (Table 1), and the overlap among individual foraging core ranges was large, resulting in datasets for Nightingale and Gough being representative (>90\%, Table 1 ). We therefore identified 2 marine IBAs located around Nightingale and Gough during the brood-guard phase (Fig. 3B,D), whereas the brood-guard data for Inaccessible did not fulfil the minimum of 10 tracked individuals required to identify a marine IBA (Table 1).

Based on our tracking data, the mean maximum foraging radius during brood-guard was $32 \mathrm{~km}( \pm 18 \mathrm{~km}$, Table 1) across all islands, and this radius was applied to all remaining colonies with no or insufficient tracking data to identify further marine IBAs (Fig. 3). These circular IBAs encompassed most of the marine IBAs identified from tracking data (Fig. 3B,D) and there- fore validated both approaches as identifying crucial foraging habitat of penguins during a key stage of their breeding cycle, the brood-guard phase. We merged all potential marine IBA polygons from adjacent colonies and propose 2 marine IBAs, namely around the Tristan archipelago and Gough, respectively. These 2 proposed marine IBAs encompass an area of $9900 \mathrm{~km}^{2}$ around the Tristan archipelago and $4760 \mathrm{~km}^{2}$ around Gough, or $2 \%$ of Tristan's EEZ when combined. Because they cover all nearshore waters surrounding breeding colonies, these 2 proposed marine IBAs are used by all penguins breeding in the Tristan da Cunha group for either commuting or foraging and therefore represent important marine habitat for 328000-393000 penguins, or 88-90\% of the species' global population (Table S1). Both identified marine IBAs fell entirely within the 50 nmi commercial fin-fisheries exclusion zone (Table 1, Fig. 1).

\section{DISCUSSION}

This study provides the first description of the atsea distribution of northern rockhopper penguins in the Tristan group during the breeding season and proposes 2 marine IBAs for the species. A number of distribution patterns emerged from the study that are of ecological interest when considering marine spatial planning for the species.

\subsection{Spatial and temporal distribution patterns}

The most obvious pattern was the stage-specific variability in distribution: incubation trips lasted for weeks and ranged for hundreds of $\mathrm{km}$ from the breeding colony, whereas brood-guard trips mostly lasted $1 \mathrm{~d}$ and ranged tens of $\mathrm{km}$ and crèche trips were bimodal, comprising a mixture of short and long trips. Many seabirds perform alternating short and long foraging trips for the purpose of chick feeding and self-maintenance, respectively (Welcker et al. 2009). Such stage-specific differences in foraging trip range are typical in congeners (e.g. Barlow \& Croxall 2002a for macaroni penguin; Hull et al. 1997 for royal penguin; Ludynia et al. 2013 and Masello et al. 2010 for southern rockhopper penguin). Northern rockhopper penguins in Tristan waters were dispersed at low densities over a wide area during self-maintenance trips (incubation and long crèche) and concentrated at high densities close to their colonies during chick provisioning trips (brood-guard and short 
crèche). For seabirds generally, the effectiveness of area-based protection declines with foraging range from the colony (Oppel et al. 2018), so for northern rockhopper penguins, the protection of specific areas around colonies will be most appropriate for safeguarding chick provisioning trips. To protect birds during their self-maintenance trips, broader measures would be more appropriate, as they can be applied across the entire EEZ (see Section 4.2 below).

We found temporal and spatial consistency in the areas used during brood-guard trips from the same colonies on Nightingale and Gough across years. Similarly, macaroni penguins at South Georgia were largely consistent in the areas used during broodguard across 5 years, although they ranged more widely in 1 year when food availability was low (Horswill et al. 2017). Likewise, trip durations for southern rockhopper penguins on Staten Island, Argentina, were consistent across 2 years during both broodguard and crèche stages (Raya Rey et al. 2007). Such consistency is to be expected: chicks need to be fed at short intervals to maintain their growth and survival (Barlow \& Croxall 2002b), which, when combined with slow movement speeds of penguins compared to flying seabirds, constrains distributions to be close to the colony (Croxall \& Davis 1999). The consistent use of similar space across years provides confidence that the protection of areas important for chick provisioning, as identified using short-term tracking data, will be an effective conservation tool in the longer term.

The foraging areas used by birds from Nightingale and Inaccessible exhibited very little overlap during brood-guard, despite the close proximity of the colonies $(25 \mathrm{~km})$ relative to the maximum foraging ranges (76 km, Table 1). Such spatial segregation has been widely noted among neighbouring seabird colonies, and arises from the interaction of locomotory costs and intraspecific competition (Wakefield et al. 2013, 2017, Bolton et al. 2019). Among Eudyptes penguins, spatial segregation among neighbouring colonies during brood-guard has been found in southern rockhopper penguins on the Falkland Islands (Masello et al. 2010) and macaroni penguins on South Georgia (Trathan et al. 2006). Apparent spatial segregation may, however, also arise in the absence of intraspecific competition if birds show directed movements towards deeper water, particularly where colonies are located on coastlines with differing orientations. This offers an alternative explanation for the largely discrete elliptical foraging areas that are oriented to the north and southeast of the Inaccessible and Nightingale colonies, respectively (Fig. 3B).
The apparent spatial segregation has important implications for the recognition of marine IBAs, since only 2 colonies in the Tristan group had sufficient tracking data to support marine IBA delineation using the method described by Lascelles et al. (2016). The strong spatial segregation evident in Eudyptes penguins during brood-guard means that the important areas identified around these 2 sites from where we had representative tracking data are unlikely to be used by birds breeding elsewhere in the Tristan group. However, particularly colonies along the north, east and west coast of Gough, and some colonies on Inaccessible are difficult and expensive to access, so tracking data to identify marine IBAs for these breeding sites is unlikely to become available in the near future. We therefore followed an alternative approach to identify marine IBAs based on the mean maximum foraging radius during brood-guard around colonies on islands holding $\geq 1 \%$ of the global population (Soanes et al. 2016).

Marked spatial segregation was evident between Nightingale and Gough during the incubation period. A similar separation has been observed for southern rockhopper penguins breeding on opposite coasts of the Falklands Islands (Pütz et al. 2003, Ludynia et al. 2013). Given that the breeding season on Gough commences about a month later than in the Tristan archipelago, this pattern is unlikely to arise from intraspecific competition, because when Gough birds are making long incubation trips, those from the northern islands are making short brood-guard trips close to their colony, leaving most of the area north of the STF vacant for Gough birds to utilise. The birds we tracked from Gough travelled south towards the Subantarctic Front, but this frontal system is beyond the range of incubation trips from Nightingale, which were instead dispersed in a longitudinal direction staying to the north of the STF. Other Eudyptes species similarly show plasticity in their use of fronts and water masses during incubation (Hull et al. 1997, Barlow \& Croxall 2002a, Ludynia et al. 2013, Pütz et al. 2018). This spatial and temporal segregation results in birds from Gough and the northern islands foraging in different water masses throughout the breeding season and potentially experiencing different threats (see Section 4.2). It also affects the scope to protect each population, as birds from Gough spend more time outside the EEZ during their incubation trips than those from Nightingale, thus entering ABNJs where marine spatial planning is more difficult to implement (Harrison et al. 2018).

In general, we encourage future researchers aiming to identify marine IBAs based on penguin track- 
ing data to focus tracking efforts on the brood-guard (small chick rearing) phase when birds are spatially most constrained (Oppel et al. 2018). While tracking efforts during other stages of the breeding cycle may be of interest to answer ecological questions, they are unlikely to identify significant areas of aggregation that will meet the representativeness threshold to be proposed as a marine IBA, following the method described by Lascelles et al. (2016).

\subsection{Recommendations for marine spatial planning}

The greatest threats to penguins globally that can be managed by marine spatial planning are overfishing, bycatch in fisheries, and marine pollution (Trathan et al. 2014, Dias et al. 2019, Ropert-Coudert et al. 2019, Boersma et al. 2020). Fisheries for sardines and anchovies off South Africa are believed to compete with African penguins Spheniscus demersus for food (Campbell et al. 2019) but the small zooplankton and fish species that comprise the diet of northern rockhopper penguins in Tristan (Booth \& McQuaid 2013) are not yet of commercial value to fisheries. Penguins' diving behaviour, however, renders them vulnerable to entanglement in fishing gear and bycatch in gillnets (Crawford et al. 2017). The use of gillnets is banned within the Tristan EEZ, but illegal gill netting in the South Atlantic in the late 1980s and early 1990s resulted in southern rockhopper penguin mortality (Ryan \& Cooper 1991), and ghost drift nets have been found in Tristan waters in the past decade (which could have been illegally set within the EEZ or drifted in from ABNJ; J. Glass pers. comm.). Ryan \& Cooper (1991) found 3 northern rockhopper penguins incidentally killed in longline fisheries, but currently this is likely a negligible mortality source (Crawford et al. 2017). The existing commercial rock lobster fishery and subsistence line fishing within the $50 \mathrm{nmi}$ zone around each island are fundamental to the Tristan community's economy and culture and are not known to adversely affect penguins.

Penguins are particularly vulnerable to oil pollution since they are unable to avoid contact with surface pollutants by flying (Crawford et al. 2000, García-Borboroglu et al. 2006). Although Tristan is a remote group of islands, it is situated on a busy shipping lane that links African, Asian and South American ports (Ryan et al. 2019), which creates a significant risk of chronic and catastrophic oil pollution (Ropert-Coudert et al. 2019). This high risk was realised in 2011 when the bulk carrier MS 'Oliva' ran aground on Nightingale and spilled fuel which killed thousands of pen- guins (Ruoppolo et al. 2013). Ship traffic is currently subject to a $10 \mathrm{nmi}$ minimum safe clearing distance around Tristan's islands, which we consider insufficient, particularly given the remote location and small community, which has limited resources to rescue stricken vessels or respond to oil spills (Ruoppolo et al. 2013). We therefore recommend the existing $50 \mathrm{nmi}$ finfish exclusion zone is closed to transiting vessels to reduce the risk of both chronic and catastrophic oil pollution. This zone encompasses all of the proposed marine IBAs identified in this study and the maximum foraging ranges of all chick provisioning trips. The measure would also benefit globally important aggregations of flying seabirds and subantarctic fur seals Arctocephalus tropicalis that occur close to shore within the EEZ during the breeding season (Dias et al. 2017, Requena et al. 2020), along with pristine nearshore benthic communities (Caselle et al. 2018). 'Areas to be avoided', that are declared by the International Maritime Organization and implemented globally, provide a suitable regulatory framework for routing shipping away from ecologically sensitive areas (Vanderlaan \& Taggart 2009).

Acknowledgements. The Tristan Conservation Department (TCD) granted permission to carry out the work and provided essential assistance in the field. This study was funded by the Royal Society for the Protection of Birds, UK, the South African National Research Foundation, the Tristan da Cunha Government, BirdLife South Africa, Darwin Plus Overseas Territories Environment and Climate Fund (grant DPLUS 053), the Prince Albert II of Monaco Foundation, the FitzPatrick Institute of African Ornithology, University of Cape Town, the South African Department of Environment, Forestry and Fisheries and the BAS/NERC Official Development Assistance Atlantic Islands Project (grant NE/R000 107/1). We are grateful to the crews on the SA 'Agulhas II', MFV 'Baltic Trader' and the MFV 'Edinburgh' for logistic support and to Nigel Butcher and Andrew Asque for customisation of the IGotU loggers. Comments from anonymous reviewers greatly improved this manuscript.

\section{LITERATURE CITED}

Agardy MT (1994) Advances in marine conservation: the role of marine protected areas. Trends Ecol Evol 9:267-270

Barlow KE, Croxall JP (2002a) Seasonal and interannual variation in foraging range and habitat of macaroni penguins Eudyptes chrysolophus at South Georgia. Mar Ecol Prog Ser 232:291-304

Barlow KE, Croxall JP (2002b) Provisioning behaviour of macaroni penguins Eudyptes chrysolophus. Ibis 144:248-258

Baylis AMM, Tierney M, Orben RA, Warwick-Evans V and others (2019) Important at-sea areas of colonial breeding marine predators on the Southern Patagonian Shelf. Sci Rep 9:8517

Beal M, Oppel S, Handley J, Pearmain L and others (2020) BirdLifeInternational/track2kba: first release (version 0.5.0). Zenodo. http://doi.org/10.5281/zenodo.3823902 
BirdLife International (2018) Eudyptes moseleyi. IUCN Red List Threat Species 2018:e.T22734408A132664126. https://dx.doi.org/10.2305/IUCN.UK.2018-2.RLTS.T22 734408A132664126.en (accessed 1 Nov 2019)

Boersma PD, Borboroglu PG, Gownaris NJ, Bost CA and others (2020) Applying science to pressing conservation needs for penguins. Conserv Biol 34:103-112

Bolton M, Conolly G, Carroll M, Wakefield ED, Caldow R (2019) A review of the occurrence of inter-colony segregation of seabird foraging areas and the implications for marine environmental impact assessment. Ibis 161: 241-259

Booth JM, McQuaid CD (2013) Northern rockhopper penguins prioritise future reproduction over chick provisioning. Mar Ecol Prog Ser 486:289-304

Borboroglu P, Boersma PD (2013) Penguins: natural history and conservation. University of Washington Press, Seattle, WA

Brown CR (1987) Traveling speed and foraging range of macaroni and rockhopper penguins at Marion Island. J Field Ornithol 58:118-125

* Calenge C (2006) The package 'adehabitat' for the R software: a tool for the analysis of space and habitat use by animals. Ecol Modell 197:516-519

Campbell KJ, Steinfurth A, Underhill LG, Coetzee JC and others (2019) Local forage fish abundance influences foraging effort and offspring condition in an endangered marine predator. J Appl Ecol 56:1751-1760

Caselle JE, Hamilton SL, Davis K, Thompson CDH and others (2018) First quantification of subtidal community structure at Tristan da Cunha Islands in the remote South Atlantic: from kelp forests to the deep sea. PLOS ONE 13:e0195167

CBD (Convention on Biological Diversity) (2010) Aichi Biodiversity Targets. https://www.cbd.int/sp/targets/ (from 5 Nov 2018)

* Crawford R, Davis S, Harding R, Jackson L and others (2000) Initial impact of the Treasure oil spill on seabirds off western South Africa. Afr J Mar Sci 22:157-176

Crawford R, Ellenberg U, Frere E, Hagen C and others (2017) Tangled and drowned: a global review of penguin bycatch in fisheries. Endang Species Res 34:373-396

Croxall JP, Davis LS (1999) Penguins: paradoxes and patterns. Mar Ornithol 27:1-12

Cuthbert RJ (2013) Northern rockhopper penguin (Eudyptes moseleyi). In: Garcia Borboroglu P, Boersma PD (eds) Penguins: natural history and conservation. University of Washington Press, Seattle, WA, p 131-143

Cuthbert RJ, Cooper J, Burle MH, Glass CJ and others (2009) Population trends and conservation status of the northern rockhopper penguin Eudyptes moseleyi at Tristan da Cunha and Gough Island. Bird Conserv Int 19:109-120

De Santo EM (2013) Missing marine protected area (MPA) targets: how the push for quantity over quality undermines sustainability and social justice. J Environ Manage 124:137-146

Dias MP, Oppel S, Bond AL, Carneiro APB and others (2017) Using globally threatened pelagic birds to identify priority sites for marine conservation in the South Atlantic Ocean. Biol Conserv 211:76-84

Nias MP, Carneiro APB, Warwick-Evans V, Harris C and others (2018) Identification of marine Important Bird and Biodiversity Areas for penguins around the South Shetland Islands and South Orkney Islands. Ecol Evol 8: 10520-10529
Dias MP, Martin R, Pearmain EJ, Burfield IJ and others (2019) Threats to seabirds: a global assessment. Biol Conserv 237:525-537

* Fieberg J, Kochanny CO (2005) Quantifying home-range overlap: the importance of the utilization distribution. J Wildl Manag 69:1346-1359

*Fox HE, Soltanoff CS, Mascia MB, Haisfield KM, Lombana AV, Pyke CR, Wood L (2012) Explaining global patterns and trends in marine protected area (MPA) development. Mar Policy 36:1131-1138

Fraley C, Raftery AE, Murphy B, Scrucca L (2012) mclust version 4 for R: normal mixture modeling for model-based clustering, classification, and density estimation. Department of Statistics, University of Washington, Seattle, WA

* Game ET, Grantham HS, Hobday AJ, Pressey RL and others (2009) Pelagic protected areas: the missing dimension in ocean conservation. Trends Ecol Evol 24:360-369

* García-Borboroglu P, Boersma PD, Ruoppolo V, Reyes L and others (2006) Chronic oil pollution harms Magellanic penguins in the Southwest Atlantic. Mar Pollut Bull 52: 193-198

* Halpern BS, Walbridge S, Selkoe KA, Kappel CV and others (2008) A global map of human impact on marine ecosystems. Science 319:948-952

* Halpern BS, Frazier M, Potapenko J, Casey KS and others (2015) Spatial and temporal changes in cumulative human impacts on the world's ocean. Nat Commun 6:7615

* Harrison AL, Costa DP, Winship AJ, Benson SR and others (2018) The political biogeography of migratory marine predators. Nat Ecol Evol 2:1571-1578

* Heerah K, Dias MP, Delord K, Oppel S, Barbraud C, Weimerskirch H, Bost CA (2019) Important areas and conservation sites for a community of globally threatened marine predators of the Southern Indian Ocean. Biol Conserv 234:192-201

*Hill R, Dyer GA, Lozada-Ellison LM, Gimona A, MartinOrtega J, Munoz-Rojas J, Gordon IJ (2015) A social-ecological systems analysis of impediments to delivery of the Aichi 2020 Targets and potentially more effective pathways to the conservation of biodiversity. Glob Environ Change 34:22-34

*Horswill C, Trathan PN, Ratcliffe N (2017) Linking extreme interannual changes in prey availability to foraging behaviour and breeding investment in a marine predator, the macaroni penguin. PLOS ONE 12:e0184114

*Hull CL, Hindell MA, Michael K (1997) Foraging zones of royal penguins during the breeding season, and their association with oceanographic features. Mar Ecol Prog Ser 153:217-228

*Johnson DS, London JM, Kuhn CE (2011) Bayesian inference for animal space use and other movement metrics. J Agric Biol Environ Stat 16:357-370

* Lascelles BG, Taylor PR, Miller MGR, Dias MP and others (2016) Applying global criteria to tracking data to define important areas for marine conservation. Divers Distrib 22:422-431

Lewis F, Butler A, Gilbert L (2011) A unified approach to model selection using the likelihood ratio test. Methods Ecol Evol 2:155-162

* Ludynia K, Dehnhard N, Poisbleau M, Demongin L, Masello JF, Quillfeldt P (2012) Evaluating the impact of handling and logger attachment on foraging parameters and physiology in southern rockhopper penguins. PLOS ONE 7: e50429

* Ludynia K, Dehnhard N, Poisbleau M, Demongin L, Masello 
JF, Voigt CC, Quillfeldt P (2013) Sexual segregation in rockhopper penguins during incubation. Anim Behav 85: 255-267

Masello JF, Mundry R, Poisbleau M, Demongin L, Voigt CC, Wikelski M, Quillfeldt P (2010) Diving seabirds share foraging space and time within and among species. Ecosphere 1:art19

O'Leary BC, Fieldhouse P, McClean CJ, Ford AES, Burns P, Hawkins JP, Roberts CM (2019) Evidence gaps and biodiversity threats facing the marine environment of the United Kingdom's Overseas Territories. Biodivers Conserv 28:363-383

* Oppel S, Bolton M, Carneiro APB, Dias MP and others (2018) Spatial scales of marine conservation management for breeding seabirds. Mar Policy 98:37-46

Orsi AH, Whitworth T III, Nowlin WD Jr (1995) On the meridional extent and fronts of the Antarctic Circumpolar Current. Deep Sea Res I 42:641-673

Patterson TA, Sharples RJ, Raymond B, Welsford DC and others (2016) Foraging distribution overlap and marine reserve usage amongst sub-Antarctic predators inferred from a multi-species satellite tagging experiment. Ecol Indic 70:531-544

Pütz K, Smith JG, Ingham RJ, Luthi BH (2003) Satellite tracking of male rockhopper penguins Eudyptes chrysocome during the incubation period at the Falkland Islands. J Avian Biol 34:139-144

Pütz K, Harris S, Ratcliffe N, Rey AR, Poncet S, Lüthi BJPB (2018) Plasticity in the foraging behavior of male southern rockhopper penguins (Eudyptes chrysocome) during incubation in the Falkland/Malvinas Islands. Polar Biol 41:1801-1814

Raya Rey A, Trathan PN, Schiavani A (2007) Inter-annual variation in provisioning behaviour of southern rockhopper penguins Eudyptes chrysocome chrysocome at Staten Island, Argentina. Ibis 149:826-835

Requena S, Oppel S, Bond AL, Hall J and others (2020) Marine hotspots of activity inform protection of a threatened community of pelagic species in a large oceanic jurisdiction. Anim Conserv 23:585-596

Ronconi RA, Lascelles BG, Langham GM, Reid JB, Oro D (2012) The role of seabirds in Marine Protected Area identification, delineation, and monitoring: introduction and synthesis. Biol Conserv 156:1-4

Ropert-Coudert Y, Knott N, Chiaradia A, Kato A (2007a) How do different data logger sizes and attachment positions affect the diving behaviour of little penguins? Deep Sea Res II 54:415-423

Ropert-Coudert Y, Wilson RP, Yoda K, Kato A (2007b) Assessing performance constraints in penguins with externallyattached devices. Mar Ecol Prog Ser 333:281-289

Ropert-Coudert Y, Chiaradia A, Ainley D, Barbosa A and others (2019) Happy feet in a hostile world? The future of penguins depends on proactive management of current and expected threats. Front Mar Sci 6:248

Ruoppolo V, Woehler EJ, Morgan K, Clumpner CJJPR (2013) Wildlife and oil in the Antarctic: a recipe for cold disaster. Polar Rec 49:97-109

Ryan PG, Cooper J (1991) Rockhopper penguins and other marine life threatened by driftnet fisheries at Tristan da Cunha. Oryx 25:76-79

Ryan PG, Dilley BJ, Ronconi RA, Connan M (2019) Rapid increase in Asian bottles in the South Atlantic Ocean indicates major debris inputs from ships. Proc Natl Acad Sci USA 116:20892-20897
RZSS (Royal Zoological Society of Scotland), BAS (British Antarctic Survey), CEBC-CNRS (Centre d'études biologiques de Chizé-Centre national de la recherche scientifique), RSPB (Royal Society for the Protection of Birds), TAAF (Terres australes et antarctiques françaises), TCD (Tristan da Cunha Conservation Department) (2018) Northern rockhopper penguin Eudyptes moseleyi action plan 2017-2027. RZSS, Edinburgh

Sala E, Lubchenco J, Grorud-Colvert K, Novelli C, Roberts C, Sumaila UR (2018) Assessing real progress towards effective ocean protection. Mar Policy 91:11-13

* Smith RJ, Bennun L, Brooks TM, Butchart SH and others (2019) Synergies between the key biodiversity area and systematic conservation planning approaches. Conserv Lett 12:e12625

* Soanes LM, Bright JA, Angel LP, Arnould JP and others (2016) Defining marine important bird areas: testing the foraging radius approach. Biol Conserv 196:69-79

Trathan PN, Green C, Tanton J, Peat H, Poncet J, Morton A (2006) Foraging dynamics of macaroni penguins Eudyptes chrysolophus at South Georgia during brood-guard. Mar Ecol Prog Ser 323:239-251

Trathan PN, Garcia-Borboroglu P, Boersma DEE, Bost CA and others (2014) Pollution, habitat loss, fishing, and climate change as critical threats to penguins. Conserv Biol 29:31-41

* Tristan da Cunha Ordinances (1983) Fisheries Limits (Tristan da Cunha) Ordinance. https://www.sainthelena.gov.sh/ wp-content/uploads/2017/12/Fishery-Limits-TdC-Ordi nance.pdf

UNEP-WCMC (UN Environment Programme World Conservation Monitoring Centre), International Union for Conservation of Nature (IUCN), National Geographic Society (NGS) (2019) Protected planet: the World Database on Protected Areas (WDPA), December 2019 version. UNEPWCMC, Cambridge. https://livereport.protectedplanet.net/ chapter-1 (accessed 13 Dec 2019)

*Vanderlaan ASM, Taggart CT (2009) Efficacy of a voluntary area to be avoided to reduce risk of lethal vessel strikes to endangered whales. Conserv Biol 23:1467-1474

WWakefield ED, Bodey TW, Bearhop S, Blackburn J and others (2013) Space partitioning without territoriality in gannets. Science 341:68-70

* Wakefield ED, Owen E, Baer J, Carroll MJ and others (2017) Breeding density, fine-scale tracking, and large-scale modeling reveal the regional distribution of four seabird species. Ecol Appl 27:2074-2091

*Welcker J, Harding AM, Karnovsky NJ, Steen H, Strøm H, Gabrielsen GW (2009) Flexibility in the bimodal foraging strategy of a high Arctic alcid, the little auk Alle alle. J Avian Biol 40:388-399

Williams TD (1995) The penguins: Spheniscidae. Oxford University Press, Oxford

Williams AJ, Stone C (1981) Rockhopper penguins Eudyptes chrysocome at Tristan da Cunha. Cormorant 9:59-66

*Wilson RP, Grant WS, Duffy DC (1986) Recording devices on free-ranging animals: Does measurement affect foraging performance? Ecology 67:1091-1093

Wilson RP, Putz K, Peters G, Culik B, Scolaro A, Charrassin JB, Ropert-Coudert Y (1997) Long-term attachment of transmitting and recording devices to penguins and other seabirds. Wildl Soc Bull 25:101-106

*Wood LJ, Fish L, Laughren J, Pauly D (2008) Assessing progress towards global marine protection targets: shortfalls in information and action. Oryx 42:340-351 